\title{
Laparoscopic versus Open Repair of Perforated Peptic Ulcer: Comparative Study
}

\author{
EL-SAYED ABDULLAH, M.D.; AHMED NEGM, M.D.; MOHAMED SAMIR, M.D.; MAGDY BASHEER, M.D.; \\ HOSAM EL-GHADBAN, M.D.; ABD EL-RAHMAN EL-BAHY, M.D.; AHMED ABD EL-MODABER, M.D.; \\ ASHRAF ABBAS, M.D.; MAHMOUD AMIN, M.D. and IBRAHIM DAWOUD, M.D.
}

The Department of General Surgery, Faculty of Medicine, Mansoura University, Mansoura, Egypt

\begin{abstract}
Background: Despite the well known benefits of minimal invasive surgery, up till now, there is a marked controversy regarding the real benefits of laparoscopic repair of Perforated Peptic Ulcer (PPU).

Aim of the Study: The early outcome results of laparoscopic and open repair of PPU were compared to assess the feasibility and safety of laparoscope.

Patients and Methods: Patients with clinical diagnosis of PPU, admitted at Mansoura University Hospital over the period between December 2013 and December 2017, were included in the study after a written consent. They were prospectively randomized for laparoscopic or open repair using pedicled omental patch technique. The pre-operative, operative, and post-operative data were collected for statistical analysis.

Results: This study comprised 80 patients, out of them ten excluded due to detection of other pathologies, 33 remained in the laparoscopic group and 37 patients in the open group. The conversion rate from laparoscopic into open technique was $(45.5 \%)$. The laparoscopic technique in comparison with the open technique showed a significantly longer operative time (61 min vs. $46.54 \mathrm{~min}$; respectively), shorter hospital stay (5.72 vs. 8.77 days; respectively), lower post-operative analgesia requirements (111.11 vs. $268.27 \mathrm{mg}$ pethidine/day; respectively), and a lower rate of wound infection (5.6\% vs. $34.6 \%$; respectively). The laparoscopic and open groups had a comparable incidence of pulmonary complications, wound dehiscence, leakage, ileus, and intra-abdominal collection. There were no mortalities in the laparoscopic group while there were 6 mortalities in the open group (11.5\%). Conversion did not affect the outcome of open repair except for prolongation of operative time.
\end{abstract}

Conclusion: Laparoscopic repair of PPU is equally feasible and safe in comparison to the open repair in patients with low surgical risk.

Key Words: Peptic ulcer-Perforation - Laparoscopy Omental patch.

Correspondence to: Dr. El-Sayed Abdullah, E-Mail: sayedabdullah311@ gmail.com

\section{Introduction}

DESPITE the marked decrease in the prevalence of peptic ulcer disease (6-15\% in the general population) as a result of the advance in its medical treatment (H2-blockers, proton pump inhibitors, and Helicobacter pylori eradication therapy), perforated peptic ulcer still represent a challenging emergency for surgeons as it occurs in 5-10\% and responsible for about $70 \%$ of the deaths of peptic ulcer disease $[\mathbf{1 , 2}]$.

The rapid progress of laparoscopic surgery has complicated the issue of the ideal approach for the management of perforated peptic ulcer [3] .

Mouret et al., applied the first laparoscopic sutureless fibrin glue fixed omental patch for perforated duodenal ulcer repair [4]. Nathanson et al., introduced the first laparoscopic sutured omental patch repair of perforated peptic ulcer [5]. Since then, several methods of laparoscopic repair have been described for closure of the perforation site and laparoscopic repair became popular worldwide [6].

Laparoscopic repair of perforated peptic ulcer has gained only partial acceptance because the advantages of the minimal invasive approach are not completely obvious. Some authors have declared that laparoscopic repair is the procedure of choice [7-9], while others have failed to prove its advantages or even recommended the traditional approach in the case of peritonitis [10-12]

Therefore, we conducted this prospective randomized study to compare the laparoscopic repair of PPU with the standard open technique to assess the feasibility and safety of laparoscope. 


\section{Patients and Methods}

This prospective randomized study was conducted at Mansoura University Hospitals (MUH), during the period from December 2013 to December 2017. Patients aged (16-70 years), with provisional diagnosis PPU (based on signs of generalized peritonitis and pneumo-peritoneum) were counseled to participate in the study and an informed consent was taken from them.

Patients with delayed presentation ( $>48$ hours), absolute contraindication for laparoscopy (uncorrectable coagulopathy, severe cardiopulmonary disease), malignant ulcers (detected by postoperative pathology), rare sites of peptic ulcer (jejunum, ileum, lower esophagus), and other complications with perforated peptic ulcer (bleeding or stenosis) were excluded from the study.

All included patients were assessed by careful and complete history taking, full clinical examination, laboratory and radiological investigations. The surgical risk assessed according to American Society of Anesthesiologists score (ASA) and Boey score. The Boey score depends on the sum of three risk factors: Pre-operative shock (SBP <90mmhg), severe medical illness (ASA grade III-V), and delayed presentation (>24 hours). Boey score 0,1 is considered low surgical risk while increasing score means increasing surgical risk [13]

\section{Randomization:}

All included patients were randomly divided into two Groups (A and B), who were managed with laparoscopic and open omental patch repair respectively. Randomization was performed by a computer-generated schedule, and the results were sealed into envelopes. The envelopes were drawn and opened in the operating room by a nurse not otherwise involved in the study.

\section{Perioperative management and follow-up:}

Perioperatively, all patients received intravenous fluids $(35 \mathrm{ml} / \mathrm{kg} /$ day as maintenance after correction of dehydration) and continued till oral intake regained, nasogastric tube decompression, parenteral analgesics (pethidine $50 \mathrm{mg} /$ dose maximum $600 \mathrm{mg}$ / day), antibiotics (ceftriaxone $1 \mathrm{gm} /$ day and metronidazole 500mg t.d.s), Proton Pump Inhibitor (PPI) (omeprazole in standard doses $40 \mathrm{mg} /$ day) and deep vein thrombosis prophylaxis (clexane 40I.U/day).

Nasogastric tube was removed once intestinal sounds regained and oral fluid intake was allowed and then increased gradually to full oral intake according to clinical progress. Patients were given a two-week course of triple therapy that included; Omeprazole, Tinidazole, and Clarithromycin for Helicobacter pylori eradication then Oral (PPI) medication were prescribed for eight weeks. Histopathological examination of the taken biopsy from gastric ulcer was done to confirm its nature (peptic or malignant). Patients were discharged when they were pain free, tolerating oral intake, without vomiting, and had no drains for followup at the outpatient department at one, two and four weeks intervals.

\section{Surgical technique:}

A team of two surgeons with adequate experience (senior staff and assistant lecturer) performed the two techniques (open and laparoscopic). Under general anesthesia, conventional open omental patch repair was performed by the standard technique though midline exploratory incision [14].

As regard the laparoscopic technique, all patients were placed in a slightly reversed Trendelenburg position (15-200). The position of the primary surgeon was either on the patient's left side or between the patient's legs according to the surgeon's preference. Through a periumbilical incision; the first port (10-mm) was inserted by the open Hasson technique for achieving pneumoperitoneum and insertion of the 300 telescope. In patients with previous abdominal surgery the first trocar was placed away from the scar of previous operation by open technique.

Carbon dioxide pneumoperitoneum was created using pressure $8-12 \mathrm{mmHg}$ with slow initial flow rate to avoid hemodynamic instability then the flow rate was increased as required.

Exploration of the peritoneal cavity was the starting step of the technique to confirm the diagnosis. Two working ports ( 10 and $5 \mathrm{~mm}$ port) were inserted under vision on the right and left hypochondrial regions. Another 5-mm port was inserted below xiphoid process, if needed, for retraction of the liver. These sites have been changed according to the build of the patient and surgeon preference in order to achieve optimal triangulation with the site of ulcer and to allow proper drainage.

The ulcer size measurement was performed in reference to the $5 \mathrm{~mm}$ diameter of the working laparoscopic instrument. Using 2-0 Vicryl suture; one, two, or three pre-taken separate stitches were inserted through the healthy tissue on both sides according to the size of the ulcer. Then, an omental patch was placed over the ulcer site and the pre- 
taken stitches were then knotted well over the omental patch. When gastric perforation was found, ulcer margins were trimmed as a biopsy. The methylene blue test, and the air-fluid leak proof test, was used as needed.

Meticulous peritoneal lavage with (2-6) liters of warm normal saline was performed under direct vision, to clear the whole peritoneal cavity especially perisplenic, subhepatic, subphrenic, and pelvic regions. Careful drainage of the peritoneal cavity with one, two, or three drains according to the severity of peritoneal contamination.

Conversion from laparoscopic into open technique was either recommended by the anesthetic team due to cardiopulmonary instability or decided by the primary surgeon due to technical difficulties according to surgeon's preference, and expertise.

\section{Data collection:}

Pre-operative data included: Age, gender, duration of symptoms, co-morbidities, previous abdominal surgeries, ulcer disease history (positive or negative), NSAIDs intake history, presence of shock. Operative data included: Mannheim Peritonitis Index (MPI), site and size of perforation, type of repair, operative time, conversion and cause of conversion. MPI is disease specific, easy scoring system for predicting the mortality in patients with secondary peritonitis (Table 1) [15]. Post-operative data included: Analgesia requirement, complications (leakage, wound infection, wound dehiscence, pulmonary complications, ileus and intra-abdominal collection), hospital stay, time to start oral intake and mortalities. All data were collected and recorded in a preformed sheet.

Table (1): Mannheim Peritonitis Index (MPI): (Muralidhar et al., 2014).

\begin{tabular}{ll}
\hline Risk factor & Weitage if any \\
\hline Age $>50$ & 5 \\
Female gender & 5 \\
Organ failure* & 7 \\
Malignancy & 4 \\
Origin of sepsis not colonic & 4 \\
Duration of symptoms $>24 \mathrm{hrs}$ & 4 \\
Generalized peritonitis & 6 \\
& \\
Peritoneal exudates: & 0 \\
Clear & 6 \\
Cloudy & 12 \\
Fecal &
\end{tabular}

\section{Endpoints:}

The endpoints of this study were; conversion rate, operative time, post-operative pain, length of hospital stay, morbidities, and mortalities.

\section{Statistical analysis:}

The statistical analysis of the data in this study was performed using the SPSS (statistical package of social science) Version 15. Numerical data was expressed as means \pm Standard Deviation (SD) and comparisons between groups were done. Suitable statistical tests (independent $t$-test, chi-square test and logistic regression test) were used to compare the results. The difference was considered statistically significant if $p$-value $\leq 0.05$.

\section{Results}

A total of 80 patients with clinical diagnosis of PPU were included in the study and randomized for laparoscopic or open repair (39 versus 41 patients; respectively). After exploration, ten patients (6 from the laparoscopy group and 4 from the open group) were excluded due to detection of other pathologies ( 3 with perforated cancer colon, 4 with perforated small intestine and 3 patients with perforated diverticular disease of the colon). Thus, 33 patients remained in the laparoscopy group and 37 patients in the open group who were included for final analysis. There were no statistically significant differences between the two groups as regard patient characteristics as shown in (Table 2). Also, there was no statistically significant difference between the two groups as regard the surgical risk according to the Boey score and ASA score (Table 3).

There were no statistically significant difference between the two groups as regard the size and site of the ulcers, (except for gastric ulcers which were found more in the open group) and the Mannheim peritonitis index (Table 4).

Fifteen patients $(45.5 \%)$ were converted from laparoscopic into open technique after initial exploration. The causes of conversion included; cardiopulmonary instability (in the form of hypotension and desaturation) after starting $\mathrm{CO} 2$ insufflation as recommended by anesthetic team $(n=7 / 33$; $21.2 \%$ ), the inability to completely drain the peritoneal cavity due to heavy pyogenic membranes $(\mathrm{n}=4 / 33 ; 12.12 \%)$, intra-peritoneal dense adhesions limiting laparoscopic manipulations $(n=2 / 33$; $6.06 \%$ ), distended bowel loops due to ileus which made laparoscopic manipulation difficult $(n=1 / 33$; $3.03 \%$ ) and difficult localization of perforated ulcer $(\mathrm{n}=1 / 33 ; 3.03 \%)$ (Table 5$)$. 
Table (2): Patient characteristics for laparoscopic and open repair groups.

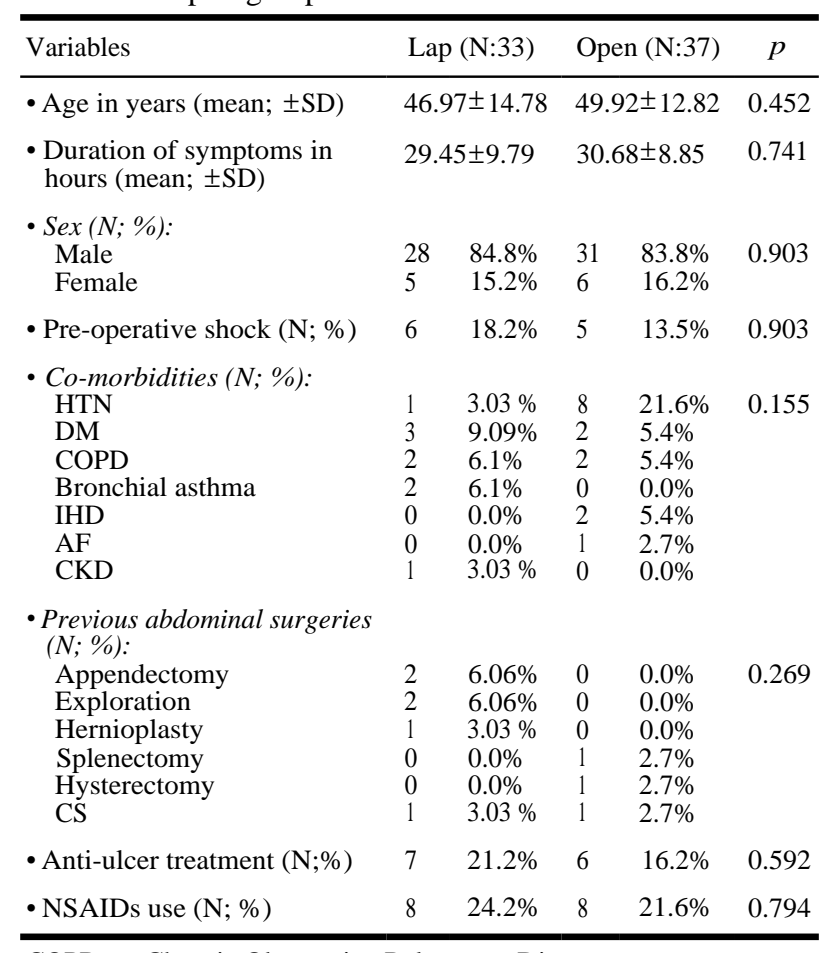

COPD : Chronic Obstructive Pulmonary Disease.

NSAIDs : Non-Steroidal Anti-Inflammatory Drugs.

Lap : Laparoscopic.

CKD : Chronic Kidney Disease. HTN: Hypertension.

AF : Atrial Fibrillation.

IHD : Ischemic Heart Disease.

DM : Diabetes Mellitus.

CS : Cesarean Section.

$\mathrm{N}$ : Number.

SD : Standard Deviation.

Table (3): Surgical risk in laparoscopic and open groups according to the Boey score and ASA score.

\begin{tabular}{llllll}
\hline & \multicolumn{2}{c}{ Lap (N:33) } & \multicolumn{2}{c}{ Open (N:37) } & \multirow{2}{*}{$p$} \\
\cline { 2 - 4 } Variables & $\mathrm{N}$ & $\%$ & $\mathrm{~N}$ & $\%$ & \\
\hline Boey score: & & & & & \\
0.00 & 11 & 33.3 & 14 & 37.8 & \multirow{2}{*}{0.227} \\
1.00 & 15 & 45.5 & 9 & 24.3 & \\
2.00 & 5 & 15.2 & 8 & 21.6 & \\
3.00 & 2 & 6.1 & 6 & 16.2 & \\
ASA score: & & & & & \\
1.00 & 25 & 75.8 & 22 & 59.5 & 0.303 \\
2.00 & 3 & 9.1 & 6 & 16.2 & \\
3.00 & 4 & 12.1 & 4 & 10.8 & \\
4.00 & 1 & 3.0 & 5 & 13.5 & \\
\hline
\end{tabular}

Lap: Laparoscopic.

$\mathrm{N}$ : Number.

Table (4): Ulcer size, ulcer site and Mannheim peritonitis index in the laparoscopic and open groups.

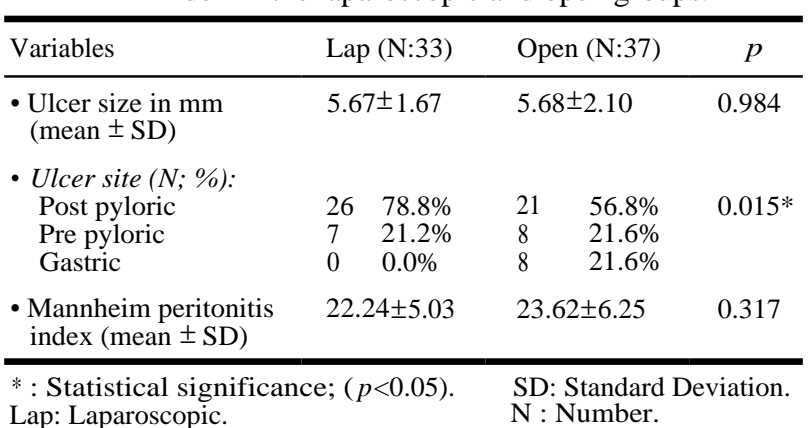

Table (5): Causes of conversion in the laparoscopic group.

\begin{tabular}{lll}
\hline & \multicolumn{2}{c}{ Laparoscopic group (N:33) } \\
\cline { 2 - 3 } Variables & $\mathrm{N}$ & $\%$ \\
\hline Cardio-pulmonary instability after & 7 & 21.2 \\
$\quad$ CO2 insufflation & & \\
Dense adhesions & 2 & 6.06 \\
Failed ulcer localization & 1 & 3.03 \\
Ileus & 1 & 3.03 \\
Incomplete drainage & 4 & 12.12 \\
\hline
\end{tabular}

CO2: Carbon dioxide

$\mathrm{N}$ : Number.

The converted cases were added to the open group, and by turn the total number of laparoscopic cases became only 18 while the open cases became 52 patients. The changes in patient characteristics of both groups after conversion are shown in (Table 6). There were statistically significant differences as regard the mean age and the ulcer size between the two groups. The patients included in the open group showed more surgical risk in comparison with those in the laparoscopic group as shown by the higher number of patients with Boey score (2, 3 ), and the higher Mannheim Peritonitis index as shown in (Table 7).

Table (6): Patient characteristics of the completed laparoscopy group and the open group after conversion.

\begin{tabular}{|c|c|c|c|c|c|}
\hline Variables & \multicolumn{2}{|c|}{ Lap (N:18) } & \multicolumn{2}{|c|}{ Open (N:52) } & $p$ \\
\hline - Age in years (mean; $\pm \mathrm{SD})$ & \multicolumn{2}{|c|}{$36.94 \pm 11.53$} & \multicolumn{2}{|c|}{$52.54 \pm 15.75$} & $<0.001 *$ \\
\hline $\begin{array}{l}\text { - Duration of symptoms in } \\
\text { hours (mean; } \pm \text { SD) }\end{array}$ & \multicolumn{2}{|c|}{$25.06 \pm 9.55$} & \multicolumn{2}{|c|}{$31.85 \pm 7.83$} & 0.104 \\
\hline $\begin{array}{l}\text { - Ulcer size in mm } \\
\text { (mean; } \pm \text { SD) }\end{array}$ & \multicolumn{2}{|c|}{$5.11 \pm .27$} & \multicolumn{2}{|c|}{$5.87 \pm 1.15$} & $0.021 *$ \\
\hline $\begin{array}{c}\text { - } \operatorname{Sex}(N ; \%): \\
\text { Male } \\
\text { Female }\end{array}$ & $\begin{array}{l}16 \\
2\end{array}$ & $\begin{array}{l}88.9 \% \\
11.1 \%\end{array}$ & $\begin{array}{l}43 \\
9\end{array}$ & $\begin{array}{l}82.7 \% \\
17.3 \%\end{array}$ & 0.534 \\
\hline - Pre-operative shock (N; \%) & 1 & $5.6 \%$ & 10 & $19.2 \%$ & 0.169 \\
\hline $\begin{array}{l}\text { - Co-morbidities }(N ; \%) \text { : } \\
\text { HTN } \\
\text { DM } \\
\text { COPD } \\
\text { Bronchial asthma } \\
\text { IHD } \\
\text { AF } \\
\text { CKD }\end{array}$ & & $\begin{array}{l}- \\
- \\
- \\
- \\
- \\
- \\
-\end{array}$ & $\begin{array}{l}9 \\
5 \\
4 \\
2 \\
3 \\
1 \\
1\end{array}$ & $\begin{array}{l}17.3 \% \\
9.6 \% \\
7.6 \% \\
3.8 \% \\
5.7 \% \\
1.9 \% \\
1.9 \%\end{array}$ & 0.105 \\
\hline $\begin{array}{l}\text { - Previous abdominal } \\
\text { surgeries }(N ; \%) \text { : } \\
\text { Appendectomy } \\
\text { Exploration } \\
\text { Hernioplasty } \\
\text { Splenectomy } \\
\text { Hysterectomy } \\
\text { CS }\end{array}$ & $\begin{array}{l}1 \\
0 \\
0 \\
0 \\
0 \\
0\end{array}$ & $\begin{array}{l}5.5 \% \\
0.0 \% \\
0.0 \% \\
0.0 \% \\
0.0 \% \\
0.0 \%\end{array}$ & $\begin{array}{l}1 \\
2 \\
1 \\
1 \\
1 \\
2\end{array}$ & $\begin{array}{l}1.9 \% \\
3.8 \% \\
1.9 \% \\
1.9 \% \\
1.9 \% \\
3.8 \%\end{array}$ & 0.785 \\
\hline - Anti-ulcer treatment $(\mathrm{N} ; \%)$ & 1 & $5.6 \%$ & 12 & $23.1 \%$ & 0.099 \\
\hline • NSAIDS use (N; \%) & 4 & $22.2 \%$ & 12 & $23.1 \%$ & 0.941 \\
\hline $\begin{array}{l}\text { COPD : Chronic Obstructiv } \\
\text { NSAIDS : Non-Steroidal Anti } \\
\text { Lap : Laparoscopic. } \\
\text { CKD : Chronic Kidney Disease } \\
\text { AF : Atrial Fibrillation. } \\
\text { IHD : Ischemic Heart Disease } \\
\text { DM : Diabetes Mellitus. }\end{array}$ & . & $\begin{array}{l}\text { Ionary I } \\
\text { amatory } \\
\text { HTN } \\
\text { CS } \\
\text { SD } \\
\text { N } \\
*\end{array}$ & $\begin{array}{l}\text { Disea } \\
\text { y Dru } \\
: \mathrm{Hy} \\
: \mathrm{Ce} \\
: \mathrm{Sta} \\
: \mathrm{Nu} \\
: \mathrm{Sta} \\
(p\end{array}$ & $\begin{array}{l}\text { ertensior } \\
\text { arean Sec } \\
\text { idard De } \\
\text { aber. } \\
\text { istical si } \\
0.05) \text {. }\end{array}$ & $\begin{array}{l}\text { ion. } \\
\text { iation. } \\
\text { nificance }\end{array}$ \\
\hline
\end{tabular}


Table (7): Boey score, ASA score and Mannheim peritonitis index for the completed laparoscopic group and the open group after conversion.

\begin{tabular}{|c|c|c|c|c|c|}
\hline \multirow{2}{*}{ Variables } & \multicolumn{2}{|c|}{ Lap (N:18) } & \multicolumn{2}{|c|}{ Open (N:52) } & \multirow{2}{*}{$p$} \\
\hline & $\mathrm{N}$ & $\%$ & $\mathrm{~N}$ & $\%$ & \\
\hline \multicolumn{6}{|l|}{ Boey score: } \\
\hline 0.00 & 10 & 55.6 & 15 & 28.8 & $0.014 *$ \\
\hline 1.00 & 8 & 44.4 & 16 & 30.8 & \\
\hline 2.00 & 0 & 0.0 & 13 & 25.0 & \\
\hline 3.00 & 0 & 0.0 & 8 & 15.4 & \\
\hline \multicolumn{6}{|l|}{ ASA score: } \\
\hline 1.00 & 16 & 88.9 & 31 & 59.6 & 0.137 \\
\hline 2.00 & 1 & 5.6 & 8 & 15.4 & \\
\hline 3.00 & 1 & 5.6 & 7 & 13.5 & \\
\hline 4.00 & 0 & 0.0 & 6 & 11.5 & \\
\hline $\begin{array}{l}\text { Mannheim peritonitis } \\
\text { index }\end{array}$ & \multicolumn{2}{|c|}{$18.89 \pm 3.05$} & \multicolumn{2}{|c|}{$24.38 \pm 5.75$} & $<0.001 *$ \\
\hline \multicolumn{6}{|l|}{$\begin{array}{ll}\text { Lap } & : \text { Laparosc } \\
\mathrm{N} & : \text { Number } \\
* & : \text { Statistica }\end{array}$} \\
\hline
\end{tabular}

Table (8) shows that the highest rate of complications was related to wound infection, pulmonary complications (chest infection, Acute Respiratory Distress Syndrome (ARDS), pleural effusion), and wound dehiscence. The incidence of leakage, ileus, intra-abdominal collection and reoperation was lower in the laparoscopy group than in the open group however, not statistically significant. Evident leakage ( 1 in the laparoscopic group and 3 in the open group), was managed with open reexploration. Intra-abdominal collections (1 in the laparoscopic group and 3 in the open group), were managed by ultrasound guided tube drainage.

Table (8): Post-operative morbidities, mortalities and reintervention rate in the completed laparoscopic group and open group.

\begin{tabular}{|c|c|c|c|c|c|}
\hline \multirow{2}{*}{ Variables } & \multicolumn{2}{|c|}{ Lap (N:18) } & \multicolumn{2}{|c|}{ Open (N:52) } & \multirow{2}{*}{$p$} \\
\hline & $\mathrm{N}$ & $\%$ & $\mathrm{~N}$ & $\%$ & \\
\hline Leakage & 1 & 5.6 & 3 & 5.8 & 0.973 \\
\hline wound infection & 1 & 5.6 & 18 & 34.6 & $0.017 *$ \\
\hline Wound dehiscence & 0 & 0.0 & 9 & 17.3 & 0.059 \\
\hline Pulmonary complications & 1 & 5.6 & 12 & 23.1 & 0.099 \\
\hline Ileus & 1 & 5.6 & 5 & 9.6 & 0.596 \\
\hline Intra-abdominal collection & 1 & 5.6 & 3 & 5.8 & 0.973 \\
\hline Mortality & 0 & 0.0 & 6 & 11.5 & 0.132 \\
\hline Reoperation & 1 & 5.6 & 3 & 5.8 & 0.973 \\
\hline
\end{tabular}

There were no mortalities in the laparoscopic group. On the other hand there were 6 mortalities in the open group (11.5\%).

The completed laparoscopy group had a significantly longer operative time, lower daily analgesia requirement and shorter hospital stay than that in the open group (Table 9).
Table (9): Operative time, post-operative analgesia requirement, and hospital stay, in the completed laparoscopy group and the open group.

\begin{tabular}{lrrc}
\hline Variables & Lap (N:33) & Open (N:37) & $p$ \\
\hline - Operative time in min & $61.67 \pm 18.55$ & $46.54 \pm 15.92$ & $<0.001^{*}$ \\
(mean; \pm SD) & & & \\
• Post-operative analgesia \\
(mg pethidine/day) \\
(mean; \pm SD)
\end{tabular}

The post-operative outcome was comparable in both the converted group and the group which started by open exploration except for a significantly longer operative time in the converted group (Table 10).

Table (10): Operative time, postoperative analgesia requirement, morbidities, re-intervention, mortalities and hospital stay in the converted laparoscopy group and open group.

\begin{tabular}{|c|c|c|c|}
\hline Variables & $\begin{array}{l}\text { Converted } \\
(\mathrm{N}: 15)\end{array}$ & $\begin{array}{l}\text { Open group } \\
(\mathrm{N}: 37)\end{array}$ & $p$ \\
\hline $\begin{array}{l}\text { - Operative time in min. } \\
\text { (mean; } \pm \text { SD) }\end{array}$ & $58.67 \pm 13.33$ & $41.62 \pm 11.90$ & $<0.001 *$ \\
\hline $\begin{array}{l}\text { - Post-operative analgesia } \\
\text { in mg/day (mean; } \pm S D)\end{array}$ & $290.00 \pm 73.68$ & $259.46 \pm 84.85$ & 0.229 \\
\hline - Leakage $(\mathrm{N} ; \%)$ & $13.3 \%$ & $2.7 \%$ & 0.136 \\
\hline - Wound infection $(\mathrm{N} ; \%)$ & $20.0 \%$ & $40.5 \%$ & 0.158 \\
\hline $\begin{array}{l}\text { - Wound dehiscence }(\mathrm{N} \\
; \%)\end{array}$ & $26.7 \%$ & $13.5 \%$ & 0.256 \\
\hline $\begin{array}{l}\text { - Pulmonary } \\
\text { complications }(\mathrm{N} ; \%)\end{array}$ & $40.0 \%$ & $16.2 \%$ & 0.065 \\
\hline $\begin{array}{l}\text { - Intra-abdominal } \\
\text { collection }(\mathrm{N} ; \%)\end{array}$ & $13.3 \%$ & $2.7 \%$ & 0.136 \\
\hline - Ileus (N ;\%) & $6.7 \%$ & $10.8 \%$ & 0.646 \\
\hline - Re-intervention $(\mathrm{N} ; \%)$ & $13.3 \%$ & $2.7 \%$ & 0.136 \\
\hline - Mortality (N ;\%) & $6.7 \%$ & $13.5 \%$ & 0.484 \\
\hline $\begin{array}{l}\text { - Hospital stay in days } \\
\text { (mean; } \pm \text { SD) }\end{array}$ & $9.27 \pm 2.83$ & $8.57 \pm 1.75$ & 0.464 \\
\hline${ }^{*} \quad: S$ & $\mathrm{~N}$ & amber & \\
\hline
\end{tabular}

\section{Discussion}

Since the first laparoscopic repair of perforated peptic ulcer by Mouret et al., [4], several clinical trials worldwide had reported the feasibility and safety of the procedure [16-18]. However, there is still a marked controversy regarding the real benefits of laparoscopic repair of perforated peptic ulcer.

The present prospective randomized study was conducted in order to assess the feasibility and safety of laparoscopic repair of PPU when compared to the standard open technique. 
In our study, patient characteristics of both groups after randomization were comparable which makes the results more dependable in contrast to the retrospective study by Lunevicius, and Morkevicius, in which they selected 60 for laparoscopic repair and 162 for open repair with the patients in the open group were significantly older, with a more delayed presentation, and with more surgical risk as indicated by the Boey score and ASA grade and by turn their results were biased towards the laparoscopic technique [7].

The rate of conversion from laparoscopic into open technique in the present study was $(45.5 \%)$ which compared favorably with the work done by Thompson et al., in their prospective study which demonstrated a conversion rate up to (60\%) [19] On the other hand, it is higher than the conversion rate reported by most of the previous studies which ranged between $(0.0 \%$ and $28.5 \%) \quad[\mathbf{1 6 , 1 8 , 2 0 ]}$. This higher conversion rate in our study can be explained by the learning curve and small number of patients who were randomly distributed between the two groups.

Lagoo et al., have declared in their retrospective study that cardiovascular instability was the most common cause of conversion, a result which was confirmed in the present study [21]. This cardiovascular instability had been explained by preoperative septic shock in patients with severe co-morbidities. On the other hand, several previous studies had reported that large ulcer size and difficult ulcer localization were the most common causes of conversion [7-9,22]. However, in our study, ulcer size did not have a marked effect on the decision of conversion duo to the used technique of pedicled omental patch which was suitable for repair of all ulcer sizes and also due to the high laparoscopic skills.

In the present study, conversion has significantly prolonged the operative time without affecting morbidities and mortalities. This was consistent with the results reported by Lee et al., in their nonrandomized prospective study [20]. On the contrary, Siu et al., had noted a poor outcome after conversion as regard morbidity and mortality rates. Additionally, conversion added scars at trocar sites, increased the cost, increased the effort of the management of a single case, and increased the operative time [16]

Laparoscopy had significantly prolonged the operative time in this study which can be explained by the large volume of warm saline (2-6 liters) used for peritoneal lavage and the intra-corporeal stitching which consumed more time than in the open repair. This was consistent with the prospective randomized controlled trial by Bertleff et al., in which they declared a significantly longer operative time in the laparoscopy group than in the open group (70min versus $50 \mathrm{~min}$, respectively) [23]. In contrast, in the retrospective study by Gloach, the operative time was significantly shorter in the laparoscopy group than in the open group (45min vs. 61min, respectively) [24]. However, this study was retrospective and patients with good general condition and early presentation were selected for laparoscopic repair while risky patients were included for open repair.

This study, like several previous studies demonstrated that post-operative pain in the completed laparoscopy group was significantly lower than that in the open group as a result of the minimally invasive nature of laparoscope with little tissue trauma $[\mathbf{7 , 2 2 , 2 3 , 2 5 ]}$. However, few studies had reported no difference between the two techniques as regard post-operative pain especially in the first few days due to the inflammatory nature of the pathology which affected the general condition of the patients $[26,27]$.

The incidence of wound infection was significantly higher in the open group due to contamination of large abdominal incisions in the open exploration by the septic peritoneal content. This result was consistent with the results of most of the previous studies $[16,17,24,28,29]$.

This study, showed also a high incidence of abdominal wall dehiscence in the open group $(17.3 \%)$ while there was no incidence of wound dehiscence in the laparoscopy group which can be explained by higher rate of wound infection affecting large midline abdominal incisions in such group of patients with poor general condition. This was consistent with the results of several previous studies $[\mathbf{7 , 2 3 , 2 4 ]}$. On the other hand Lau et al., in their prospective randomized study showed a higher incidence of abdominal wall dehiscence however not statistically significant in the laparoscopy group than in the open group (4 laparoscopic versus 2 open) [28].

The leakage rate in the laparoscopy group in this study was lower than that in the open group however not statistically significant which confirms the efficiency of the used technique and the high laparoscopic skills of the surgeons. This was consistent with the work done by Bhogal et al., in which the authors reported no suture site leak in the laparoscopy group while there was a leakage 
rate of about $(6 \%)$ in the open group [31]. In contrast, many of the previous studies had reported no significant difference in the leakage rate between the two groups $[\mathbf{2 2 , 2 3 , 2 8 ]}$.

The rate of pulmonary complications in our study was lower in the laparoscopy group than in the open group however, not reaching the level of statistical significance. This can be explained by the higher incidence of co-morbidities in the open group, delayed presentation and also due to small number of patients. This was consistent with the work done by Wilhelmsen et al., in which they showed that the rate of pulmonary complications in the laparoscopy group was lower than that in the open group [18]. On the contrary, Naesgaard et al., in their non-randomized retrospective study had found a significantly higher incidence of chest problems in laparoscopic group which had been explained by bacterial translocation as a result of pneumoperitoneum [27].

The rate of intra-abdominal collections in the laparoscopy group was lower than that in the open group however not statistically significant. This can be explained by the effective irrigation and drainage of the peritoneal cavity reaching deep peritoneal recesses during laparoscopy. In contrast, several previous studies had reported a higher rate of intra-abdominal collections following laparoscopic repair of perforated peptic ulcer $[\mathbf{7 , 2 2 , 2 8 , 2 9 ]}$ Other studies reported no difference between the two techniques as regard intra-abdominal septic complications [25,32].

This study demonstrated that the rate of postoperative ileus was lower in the laparoscopy group than in the open group however not statistically significant. This was explained by better drainage of the abdominal cavity with less manipulation when compared with the open technique. This was consistent with the results of several previous studies $[7,12,25,33]$.

In this study, there was no mortality in laparoscopic group while there were 6 mortalities (11.5\%) in the open group. This higher mortality rate in the open group was not related to the technique itself but it was explained by their older age, associated co-morbidities, and severe sepsis. This was consistent with the work done by Lunevicius and Morkevicius, which showed a statistically significant lower mortality rate in the laparoscopy group than in the open group [7]. Several previous studies have found no significant difference between open and laparoscopic approach as regard mortality rate $[22,23,25,34]$
The hospital stay in our study was significantly shorter in the laparoscopic group. This was comparable to the results of multiple previous studies [23-25]. On the other hand, other studies had reported nearly equal hospital stay in both groups due to the old age of the patients with multiple comorbidities which necessitate prolonged hospital stay for improving the general condition $[\mathbf{1 2 , 3 4 ]}$.

In our study, only one patient in the laparoscopy group and three patients in the open group were surgically re-explored due to evident leakage. This was consistent with the work done by Bertleff et al., in which the one patient in the laparoscopy group and 2 patients in the open group were surgically re-explored [23]. In contrast a study by Siu et al., has reported a significantly higher rate of re-intervention after laparoscopic repair of PPU (6 explorations) when compared to open surgery (1 exploration) due to Leakage. This high rate of re-exploration in this study can be attributed to the high leakage rate caused by the technique of single stitch which had been used by the authors in this study [22].

This study has several limitations especially the learning curve and small number of included patients.

\section{Conclusion:}

Laparoscopic repair of perforated peptic ulcer is equally feasible and safe in comparison to the open repair in patients with low surgical risk (Boey score 0 and 1$)$.

\section{References}

1- YUAN Y., FORD A.C. and KHAN K.J.: Optimum duration of regimens for Helicobacter pylori eradication. Cochrane Database Syst. Rev., 12: Cd008337, 2013.

2- CAO F., LI J., LI A., FANG Y., WANG Y.J. and LI F.: Nonoperative management for perforated peptic ulcer: Who can benefit? Asian J. Surg., 37 (3): 148-53, 2014.

3- HUNG-CHIEH L., SHIH-CHI W., HUNG-CHANG H., CHUN-CHIEH Y., JUI-CHIEN H. and CHI-HSUN H.: Laparoscopic Simple Closure Alone is Adequate for Low Risk Patients with Perforated Peptic Ulcer. World J. Surg., 35: 1873-8, 2011.

4- MOURET J., FRANCOIS Y., VIGNAL J., BARTH X. and LOMBARD R.: Laparoscopic treatment of perforated duodenal ulcer. Br. J. Surg., 77: 1006, 1990.

5- NATHANSON L.K., EASTER D.W. and CUSCHIERI A.: Laparoscopic repair peritoneal toilette of perforated duodenal ulcer. Surg. Endosc., 4: 232-3, 1990.

6- AL-WADAANI H.: Emergent laparoscopy in treatment of perforated peptic ulcer: A local experience from a 
tertiary centre in Saudi Arabia. World Journal of Emergency Surgery, 8: 10, 2013.

7- LUNEVICIUS R. and MORKEVICIUS M.: Management strategies, early results, benefits and risk factors of laparoscopic repair of perforated peptic ulcer. World J. Surg., 29: 1299-310, 2005a.

8- VAIDYA B.B., GARG C.P. and SHAH J.B.: Laparoscopic repair of perforated peptic ulcer with delayed presentation. J. Laparoendosc. Adv. Surg. Tech., 19 (2): 153-6, 2009.

9- THORSEN K., GLOMSAKER T.B., VON MEER A., SØREIDE K. and SØREIDE J.A.: Trends in diagnosis and surgical management of patients with perforated peptic ulcer. J. Gastrointest. Surg., 15 (8): 1329-35, 2011.

10- MATSUDA M., NISHIYAMA M., HANAI T., SAEKI S. and WATANABE T.: Laparoscopic omental patch repair for perforated peptic ulcer. Ann. Surg., 221 (3): 236-40, 1995.

11-ROBERTSON G.S., WEMYSS-HOLDEN S.A. and MADDERN G.J.: Laparoscopic repair of perforated duodenal ulcers. The role of laparoscopy in generalized peritonitis. Ann. R. Coll. Surg. Engl., 82: 6-10, 2000.

12- LAU H.: Laparoscopic repair of perforated peptic ulcer: A meta-analysis. Surg. Endosc., 18: 1013-21, 2004.

13- GRAHAM R.R.: Technical surgical procedures for gastric and duodenal ulcer. Surg. Gynecol. Obstet., 66: 269-87, 1938.

14- BOEY J., CHOI S.K., POON A. and ALAGARATNAM T.T.: Risk stratification in perforated duodenal ulcers. A prospective validation of predictive factors. Ann. Surg., 205: 22-6, 1987.

15- MURALIDHAR V., MADHU C., SUDHIR S. and MADHU.: Efficacy of Mannheim Peritonitis Index (Mpi) Score in Patients with Secondary Peritonitis. Journal of Clinical and Diagnostic Research; Dec., Vol.-8 (12): NC01-NC03, 2014.

16- SIU W.T., CHAU C.H., LAW B.K.B., TANG C.N., HA P.Y. and LI M.K.W.: Routine use of laparoscopic repair for perforated peptic ulcer. Br. J. Surg., 91: 481-4, 2004.

17- STAVROS ANTONIOU, GEORGE A., OLIVER O., RUDOLPH P., FRANK A. and GRANDERATH: Metaanalysis of Laparoscopic Versus Open Repair of Perforated Peptic Ulcer. J.S.L.S., 17: 15-22, 2013.

18- WILHELMSEN M., MØLLER M.H. and ROSENSTOCK S.: Surgical complications after open and laparoscopic surgery for perforated peptic ulcer in a nationwide cohort. Br. J. Surg., 102 (4): 382-7, 2015.

19- THOMPSON A.R., HALL T.J., ANGLIN B.A. and SCOTT-CONNER C.E.H.: Laparoscopic plication of perforated ulcer: Results of a selective approach. South Med. J., 88: 185-9, 1995.

20- LEE F.Y., LEUNG K.L., LAI B.S., NG S.S., DEXTER S. and LAU W.Y.: Predicting mortality and morbidity of patients operated on for perforated peptic ulcers. Arch. Surg., 136 (1): 90-4, 2001.

21- LAGOO S., Mc MAHON R.L., KALKHARU M., PAPPAS T.N., and EUBANKS S.: The sixth decision regarding perforated duodenal ulcer. J.S.L.S., 6: 359-68, 2002.
22- SIU W.T., LEONG H.T., LAW B.K., CHAU C.H., LI A.C., FUNG K.H., et al.: Laparoscopic repair for perforated peptic ulcer: A randomized controlled trial. Ann. Surg., 235: 313-9, 2002.

23- BERTLEFF M.J., STEGMANN T., LIEM R.S., KORS G., ROBINSON P.H., NICOLAI J.P., et al.: Comparison of closure of gastric perforation ulcers with biodegradable lactide-glycolide-caprolactone or omental patches. J.S.L. S., 13 (4): 550-43, 2009.

24- VISHWANATH GOLASH: Ten-Year Retrospective Comparative Analysis of LaparoscopicRepair versus Open Closure of Perforated Peptic Ulcer. Oman Medical Journal, (23) 4: 241-6, 2008.

25- SANABRIA A.E., MORALES C.H. and VILLEGAS M.I.: Laparoscopic repair for perforated peptic ulcer disease. Cochrane Database Syst. Rev., (4): CD004778, 2013.

26- JOHANSSON B., HALLERBACK B., GLISE H., JOHNSSON E.: Laparoscopic suture closure of perforated peptic ulcer. A nonrandomized comparison with open surgery. Surg. Endosc., 10: 656-8, 1996.

27- NAESGAARD J.M., EDWIN B., REIERTSEN O., TRONDSEN E., FAERDEN A.E. and ROSSELAND A.R.: Laparoscopic and open operation in patients with perforated peptic ulcer. Eur. J. Surg., 165: 209-14, 1999.

28- LAU W.Y., LEUNG K.L., KWONG K.H., DAVEY C., ROBERTSON C., DAWSON J.J., et al.: A randomized study comparing laparoscopic versus open repair of perforated peptic ulcer using suture or sutureless technique. Ann. Surg., 224 (2): 131-8, 1996.

29- KATKHOUDA N., MAVOR E., MASON R.J., ISAAC J.R. and TEKANT Y.: Laparoscopic repair of perforated duodenal ulcers: Outcome and efficacy in 30 consecutive patients. Arch. Surg., 134: 845-50, 1999.

30- SEELIG M.H., SEELIG S.K., BEHR C. and SCHONLEBEN K.: Comparison between open and laparoscopic technique in the management of perforated gastroduodenal ulcers. J. Clin. Gastroenterol., 37 (3): 226-9, 2003.

31- BHOGAL R.H., ATHWAL R., DURKIN D., DEAKIN M. and CHERUVU C.N.: Comparison between open and laparoscopic repair of perforated peptic ulcer disease. World J. Surg., 32: 2371-4, 2008.

32- TOMTITCHONG P., SIRIBUMRUNGWONG B., VILAICHONE R.K., KASETSUWAN P., MATSUKURA N. and CHAIYAKUNAPRUK N.: Systematic review and meta-analysis: Helicobacter pylori eradication therapy after simple closure of perforated duodenal ulcer. Helicobacter., 17: 148-52, 2012.

33- ARNAUD J.P., TUECH J.J., BERGAMASCHI R., PESSAUX P. and REGENET N.: Laparoscopic suture closure of perforated duodenal peptic ulcer. Surg. Laparosc. Endosc. Percutan. Tech., 12 (3): 145-7, 2002.

34- KIRSHTEIN B., BAYME M., MAYER T., LANTSBERG L., AVINOACH E. and MIZRAHI S.: Laparoscopic treatment of gastroduodenal perforation: Comparison with conventional surgery. Surg. Endosc., 19 (11): 1487-90, 2005. 


\section{إصلاح بالمنظار الجراحى للقرحة الهضمية المثثقوبة الهمرية

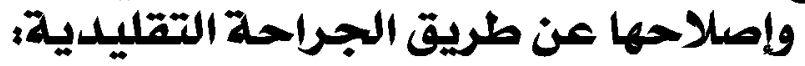 دراسة مقارنة}

مقدمة: لقد إكتسب إصلاح المنظار للقرحة الهضمية المثقوبة قبول جزئى فقط حتى الآن لآن مزايا المنظار ليست واضحة تماما. هدف البحث: إجراء مقارنة بين إصلاح ثقب القرحة الهضمية بواسطة منظار البطن الجراحى وإصلاحها عن طريق الجراحة التقليدية من حيث الإستخدام الآمن.

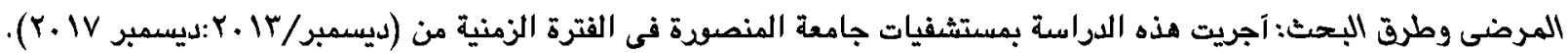

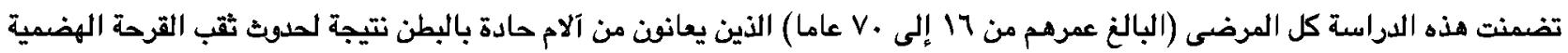

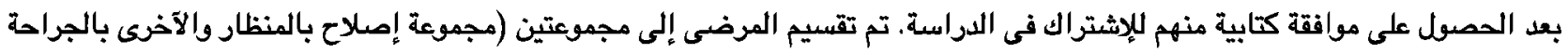

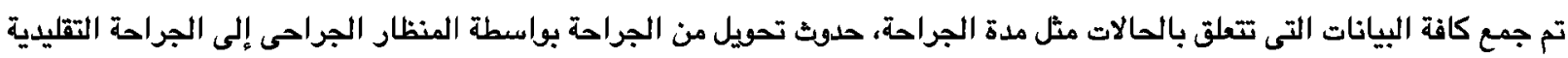

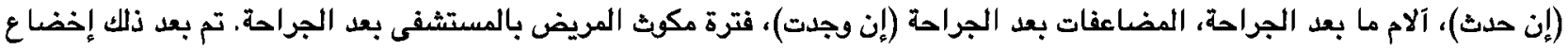
كل تلك البيانات لطرق الإحصاء المختفة الحصول على النتائج.

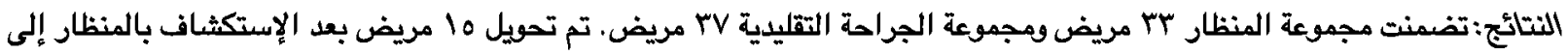

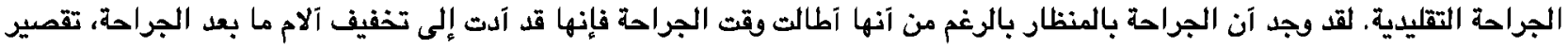

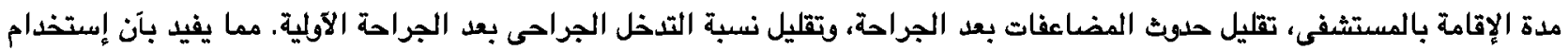

